\title{
The Impact of Risk Anomalies on the Pharmaceutical Sector of the Indian Stock Market A comparative analysis between pharmaceutical, FMCG and IT companies
}

\author{
PRAKASH PINTO ${ }^{1}$, IQBAL THONSE HAWALDAR ${ }^{2}$, GURUPRASAD KEMMINJE ${ }^{3}$, BABITHA ROHIT ${ }^{1}$, \\ CRISTI MARCEL SPULBAR ${ }^{4}$, FELICIA RAMONA BIRAU ${ }^{5 *}$, CRISTIAN VALERIU STANCIU ${ }^{4}$ \\ ${ }^{1}$ St. Joseph Engineering College, Department of Business Administration, Vamanjoor, Mangaluru Karnataka 575028, India \\ ${ }^{2}$ Kingdom University, College of Business Administration, 3903 Istiklal Street - Riffa, Bahrain \\ ${ }^{3}$ Zonal Associate Confederation of Indian Industry, Mangalore, India \\ ${ }^{4}$ University of Craiova, Faculty of Economics and Business Administration, 13 A.I. Cuza Str., 200396, Craiova, Romania \\ ${ }^{5}$ University of Craiova, Faculty of Social Science, 2 Petru Rares Str., 200349, Craiova, Romania
}

The main purpose of this research article is to provide a comparative framework on various implications of risk anomalies on Indian stock market based on an empirical study for the following sectors: Pharmaceutical, FastMoving Consumer Goods (FMCG) and IT. Risk anomaly is a notable anomaly because it is continual and allinclusive. This research study aims to examine the existence of risk anomaly in the National Stock Exchange, India, and in particular providing a comparative analysis on the behavior of the pharmaceutical sector in India.

Keywords: risk anomaly, pharmaceutical sector, stock market, volatility portfolios, risk-adjusted returns

The pharmaceutical sector in India has reached a value of about US\$ 33 billion in 2017. According to official statistics provided by Ministry of Commerce \& Industry, Government of India, this emerging country is the largest worldwide provider of generic drugs. The pharmaceutical industry in India supplies over 50\% of global demand for various vaccines, $40 \%$ of generic demand in the US and $25 \%$ of all medicine in UK. In addition, over $80 \%$ of the antiretroviral drugs used globally to combat AIDS (Acquired Immune Deficiency Syndrome) are supplied by Indian pharmaceutical firms [1]. The pharmaceutical sector in India is highly regulated, unlike FMCG and IT Sectors. Traditional investment theory holds that there exists a direct linear relationship between the risk and returns. In an efficient market, investors are said to gain higher average returns over the safe stocks only by taking above-average risks, an axiom upon which the Capital Asset Pricing Model was designed. However, the tumble experienced in the financial markets over the past several years must lead the investors to look for a better resistant strategy that offers greater stability.

Most of the research studies conducted during the period 1968 to 2008 revealed that low volatility portfolios offered enviable higher returns thus leading to the popularity of low volatility anomaly over the past decade $[1,2,3,4]$. The risk anomaly in the stock market can be exploited using the following investment strategies: 1) Low Volatility (LV) PortfolioThis strategy sorts all the stocks by their volatility and/or beta and then ranks the stocks from lowest beta and/or volatility to highest beta and/or volatility, and 2) Minimum Variance (MV) Portfolio- This relies on observations and/or estimates of correlations of individual stocks. Minimum Variance Portfolio includes a portfolio created by optimal diversification producing minimum risk. On applying these strategies, it was found that low-risk portfolios have consistently outperformed market index as well as high-risk portfolios. The low volatility investment strategy is significant in the sense that it has been able to achieve higher absolute returns as well as risk-adjusted returns consistently.

\section{Experimental part}

The study involves a process of portfolio formation and measures adopted in evaluating the portfolios for demonstrating the prevalence of risk anomaly in the stock assets traded in National Stock Exchange (NSE). Thus, the selection of stocks from the concerned sectors based on their volumes traded becomes the primary objective. Accordingly, for the present study twelve stocks have been identified from CNX NIFTY 200, along with their sectoral indices CNX FMCG Index, CNX Pharma Index and CNX IT Index respectively. The stocks thus selected have already proven the existence of the inverse relationship between risk and return, where the period of the study was limited to 5 years. However, for the present study closing values of the shortlisted stocks of NSE are tabulated for ten years along with that of CNX NIFTY 200 market index. Table 1 shows the list of stocks chosen for analysis. Pharmaceutical sector includes the following sample companies: Cipla Ltd., Divi's Laboratories Ltd., Dr. Reddy's Laboratories Ltd., GlaxoSmithKline, Pharmaceuticals Ltd., FMCG sector includes: Britannia Industries Ltd., Gillette India Ltd., GlaxoSmithKline Consumer,

\footnotetext{
*email:ramona.f.birau@gmail.com
} 
Healthcare Ltd., Hindustan Unilever Ltd., and IT sector includes: Infosys Ltd., Oracle Financial Services, Software Ltd., Wipro Ltd., Tata Consultancy, Services Ltd. Daily closing prices of all the selected stocks of the concerned sectors and daily closing prices of the relevant CNX NIFTY 200 were collected.

The average monthly closing price for each of the stocks was calculated for all the sectors including the CNX NIFTY for the concerned study period between 2005 and 2015, i.e., ten years. This was followed by computing monthly returns of each stock along with the CNX NIFTY 200 index. Once the portfolios are arranged in the decreasing order the top 6 stocks are classified to be high volatile (HV) stocks and the remaining lower six stocks form the low volatile (LV) stocks based on which the risk-return nature of portfolios are measured. The average returns of each of the portfolios for the respective months are then calculated using the formula: $\mathbf{P 1}=\left(\mathbf{S}_{\mathbf{I}}+\mathbf{S}_{\mathbf{2}}+\mathbf{S}_{\mathbf{3}}+\mathbf{S}_{\mathbf{4}}+\mathbf{S}_{\mathbf{5}}+\mathbf{S}_{\mathbf{6}}\right) / \mathbf{6}$. Here $\mathbf{P 1}$ represents the monthly average return for the first portfolio. $\mathbf{S}$ indicates the stock return and the subscript indicates the stock number. It is followed by the computation of the standard deviation of the monthly portfolios formed for 120 months, i.e., ten years. This monthly portfolio standard deviation and the average returns are then reduced to an average for six months (half yearly representation). For ease of presentation and analysis, high volatile and low volatile portfolios are represented by P1 to P20 and P21 to P40 respectively (the values are presented in the appendix). Similarly, using the closing prices of the market indices, monthly returns and standard deviations are computed for CNX NIFTY 200, which are then averaged for six months, from MP1 to MP20 (the values are presented in the appendix).

The portfolios are compared against the market index for better analysis. Sharpe ratio for the present study is computed annually to determine portfolio performance. Higher the ratio better is the risk/return trade off. Sharpe ratio is determined using the formula: Sharpe Ratio $=\left(\frac{R_{p}-R_{f}}{A S D}\right)$, where $\mathrm{R}_{\mathrm{f}}$ is the risk-free rate (repo rate), $\mathrm{Rp}$ is the average returns of the high volatile and low volatile portfolios for the entire period, while ASD is the Average Standard Deviation of a sector for the entire period". Similarly, the returns and the standard deviation are calculated for all the sectors and are tabulated. For the study repo rate of $8 \%$ is taken as a risk-free rate for all calculation purposes.
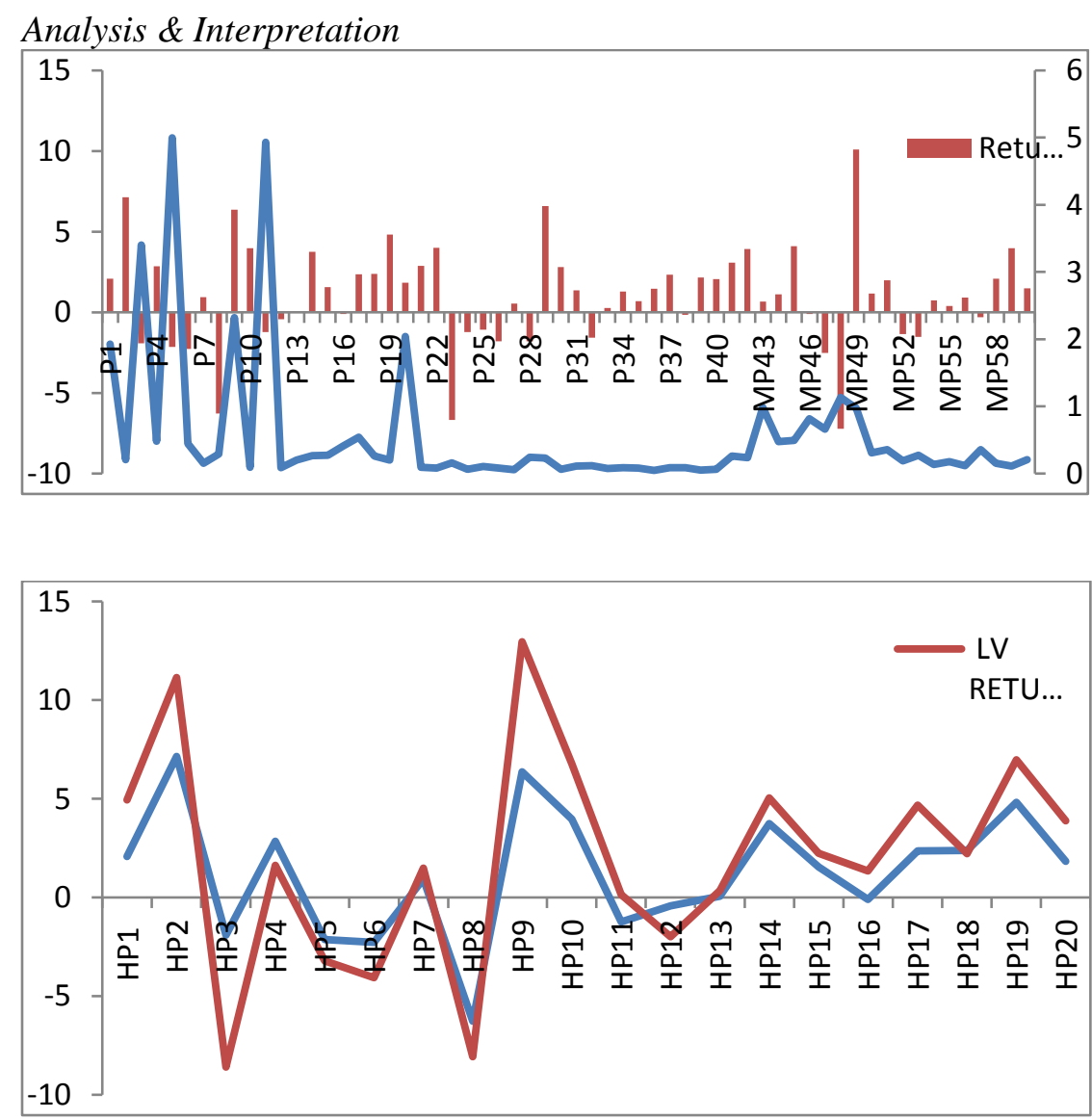

Fig. 1. Std. Deviation $v s$. Returns for HV, LV \& CNX200
Fig. 2. HV Returns vs LV Returns 
Table 1

HALF YEARLY VOLATILITY PORTFOLIOS

\begin{tabular}{|c|c|c|c|c|c|c|}
\hline \multicolumn{4}{|c|}{ Half Yearly High Volatility Portfolios } & \multicolumn{3}{|c|}{ Half Yearly Low Volatility Portfolios } \\
\hline Portfolio Month & Portfolio No. & Std. Dev. & Returns & Portfolio No. & Std. Dev. & Returns \\
\hline APRIL - SEPT 05 & $\mathrm{P}-1$ & 1.9274 & 2.0795 & $P-21$ & 0.0905 & 2.8695 \\
\hline SEPT - MARCH 06 & $\mathrm{P}-2$ & 0.2060 & 7.1447 & $\mathrm{P}-22$ & 0.0789 & 3.9971 \\
\hline APRIL - SEPT 06 & $\mathrm{P}-3$ & 3.4006 & -1.9204 & $P-23$ & 0.1599 & -6.6743 \\
\hline SEPT - MARCH 07 & $\mathrm{P}-4$ & 0.4787 & 2.8483 & $\mathrm{P}-24$ & 0.0621 & -1.2165 \\
\hline APRIL - SEPT 07 & $\mathrm{P}-5$ & 4.9972 & -2.1385 & $P-25$ & 0.1037 & -1.0714 \\
\hline SEPT - MARCH 08 & $P-6$ & 0.4447 & -2.2667 & $P-26$ & 0.0798 & -1.8045 \\
\hline APRIL - SEPT 08 & $\mathrm{P}-7$ & 0.1506 & 0.9372 & $\mathrm{P}-27$ & 0.0551 & 0.5460 \\
\hline SEPT - MARCH 09 & $\mathrm{P}-8$ & 0.2879 & -6.2709 & $P-28$ & 0.2413 & -1.8092 \\
\hline APRIL - SEPT 09 & $P-9$ & 2.3211 & 6.3735 & $P-29$ & 0.2305 & 6.5828 \\
\hline SEPT - MARCH 10 & $P-10$ & 0.0944 & 3.9686 & $P-30$ & 0.0658 & 2.7990 \\
\hline APRIL - SEPT 10 & $\mathrm{P}-11$ & 4.9306 & -1.2375 & $P-31$ & 0.1123 & 1.3722 \\
\hline SEPT - MARCH 11 & $\mathrm{P}-12$ & 0.0892 & -0.4282 & $\mathrm{P}-32$ & 0.1180 & -1.5638 \\
\hline APRIL - SEPT 11 & $P-13$ & 0.2010 & 0.0634 & $P-33$ & 0.0725 & 0.2791 \\
\hline SEPT - MARCH 12 & $\mathrm{P}-14$ & 0.2674 & 3.7447 & $\mathrm{P}-34$ & 0.0853 & 1.2897 \\
\hline APRIL - SEPT 12 & $P-15$ & 0.2741 & 1.5509 & $\mathrm{P}-35$ & 0.0795 & 0.6831 \\
\hline SEPT - MARCH 13 & $P-16$ & 0.4116 & -0.0994 & $P-36$ & 0.0468 & 1.4501 \\
\hline APRIL - SEPT 13 & $P-17$ & 0.5436 & 2.3601 & $P-37$ & 0.0871 & 2.3254 \\
\hline SEPT - MARCH 14 & $\mathrm{P}-18$ & 0.2626 & 2.3836 & $\mathrm{P}-38$ & 0.0842 & -0.1594 \\
\hline APRIL - SEPT 14 & $P-19$ & 0.2016 & 4.8274 & $P-39$ & 0.0540 & 2.1544 \\
\hline SEPT - MARCH 15 & $P-20$ & 2.0402 & 1.8269 & $P-40$ & 0.0637 & 2.0650 \\
\hline
\end{tabular}

Table 2

HALF YEARLY CNXNIFTY 200

\begin{tabular}{|c|c|c|c|}
\hline \multicolumn{4}{|c|}{ Half Yearly CNX NIFTY 200 } \\
\hline Portfolio Month & Portfolio No. & Std. Dev. & Returns \\
\hline APRIL - SEPT 05 & MP - 41 & 0.2607 & 3.0768 \\
\hline SEPT - MARCH 06 & MP - 42 & 0.2369 & 3.9339 \\
\hline APRIL - SEPT 06 & MP - 43 & 0.9837 & 0.6530 \\
\hline SEPT - MARCH 07 & MP - 44 & 0.4755 & 1.1070 \\
\hline APRIL - SEPT 07 & MP - 45 & 0.4918 & 4.0961 \\
\hline SEPT - MARCH 08 & MP - 46 & 0.8144 & -0.1159 \\
\hline APRIL - SEPT 08 & MP - 47 & 0.6631 & -2.5215 \\
\hline SEPT - MARCH 09 & MP - 48 & 1.1314 & -7.2173 \\
\hline APRIL - SEPT 09 & MP - 49 & 0.9716 & 10.0916 \\
\hline SEPT - MARCH 10 & MP - 50 & 0.3052 & 1.1704 \\
\hline APRIL - SEPT 10 & MP - 51 & 0.3570 & 1.9919 \\
\hline SEPT - MARCH 11 & MP - 52 & 0.1897 & -1.3604 \\
\hline APRIL - SEPT 11 & MP - 53 & 0.2714 & -1.5297 \\
\hline SEPT - MARCH 12 & MP - 54 & 0.1327 & 0.7328 \\
\hline APRIL - SEPT 12 & MP - 55 & 0.1740 & 0.3946 \\
\hline SEPT - MARCH 13 & MP - 56 & 0.1181 & 0.9212 \\
\hline APRIL - SEPT 13 & MP - 57 & 0.3574 & -0.2976 \\
\hline SEPT - MARCH 14 & MP - 58 & 0.1500 & 2.0874 \\
\hline APRIL - SEPT 14 & MP - 59 & 0.1097 & 3.9753 \\
\hline SEPT - MARCH 15 & MP - 60 & 0.2093 & 1.4755 \\
\hline
\end{tabular}

The following analysis includes half yearly portfolios of HV \& LV stocks along with the market index, whose risk and return are analyzed. It is observed that a portfolio containing low volatility stocks genuinely outperform high volatility 
stocks and market index for the period under consideration. On analyzing the risk v/s return trajectory between high, low volatile and market index, it is observed that P-29 (Portfolio - 29) of low volatile stocks yields a return of 6.5828 by absorbing a risk of $23 \%$. On comparing the same with the performance of high volatile stocks and market indices during the same period, it is observed that HV portfolio is yielding a return of 6.3726 and the risk involved in attaining the said return was $232.11 \%$. Likewise, market indices for the same time horizon are offering a return of 10.0916 by soaking a risk of $97.1 \%$. On evaluating the performance of portfolios of high volatility (HV), low volatility (LV) stocks and market indices for the period under study, it can be advocated that investing in LV stocks is most feasible over HV stocks and market indices. The statement is vindicated by the following substantiation. Further analysis of the HV, LV stocks and market indices of half yearly portfolios, reveals that P-21 of LV stock yields a return of 2.8694 absorbing a risk of barely $9 \%$, while the HV portfolio (P-1) stocks provide a return of 2.0795 at a risk of $192 \%$, while the market index (MP-41) during the same phase is getting a return of 3.0768 with the risk factor at $26.06 \%$. Similarly, P-22 of LV stocks accumulates a return of 3.9970 by bearing a nominal risk of $7.8 \%$, whereas P-2 of HV stocks is yielding 7.1447 and the risk involved in attaining this return is $20.5 \%$. For the same time horizon, market index (MP-42) presented returns of 3.9339 by accumulating a beta of $23.6 \%$. It is observed that at times the returns earned on HV stocks and market index may be relatively higher than the LV stocks, but the risk involved in realizing a high return from them is very significant. Hence if the same investment is made on LV stocks the returns earned would be substantially higher than when invested on HV stocks and market indices. It can be stated that the risk involved in earning a negative return is lower in LV stocks as compared to HV stocks. The same reasoning holds good while considering P-7 HV stocks and P-27 of LV stocks and MP-47 respectively, wherein it is observed that portfolio seven is yielding a return of 0.9371 while portfolios 27 and 47 are delivering returns of 0.5460 and -2.5215 respectively. Beta involved in attaining these returns was found to be $15.06 \%, 5.5 \%$ and $66.3 \%$ for $\mathrm{HV}, \mathrm{LV}$ and market index respectively.

From the above analysis, it is observed that LV portfolio returns have consistently delivered better performance for the risks offered by these portfolios. Likewise, LV portfolios 30, 34, 35 and 39 are offering returns of 2.7989, 1.2896, 0.6831 and 2.1544 bearing a risk of $6.58 \%, 8.52 \%, 7.94 \%$ and $5.39 \%$ whereas $\mathrm{HV}$ portfolios $10,14,15$ and 19 is sustaining a risk of $9.44 \%, 26.73 \%, 27.40 \%$ and $20.15 \%$ thus projecting a return of $3.9685,3.7446,1.5509$ and 4.8274 respectively. On considering the performance of the market during the same time frame, it is observed that market indices have been earning returns of $1.1704,0.7327,0.3945$ and 3.9753 enduring risks of $30.51 \%, 13.2 \%, 17.4 \%$ and $10.97 \%$ respectively for market portfolios. However, it is to be noted that even though the return offered by LV portfolio is relatively lesser than the returns offered by HV portfolio, the gap between the beta incurred by HV and LV portfolios is meager. Hence in such situations investing in LV portfolio stocks is highly preferred over HV stocks as LV stocks are relatively much safer and less volatile than HV stocks. A similar movement is observed in P-11 of HV stocks as it secures a return of -1.2374 , while for the same span P-31 of LV and P-51 of the market index is garnering a return of 1.3722 and 1.9919 attracting a risk of $493.01 \%, 11 \%$ and $35.70 \%$ respectively. On further assessing the risk v/s return, it is observed that P-33 of LV stock realizes a return of 0.279 by taking the risk of $7 \%$ unlike the portfolio of HV stock which earned a return of 0.0634 and the beta incurred was $20.1 \%$. Here again, we find that the LV portfolio is outperforming the market index (MP-53), as the market is offering a negative return of -1.5297 at a beta of $27.13 \%$. It is also found that P-36 of LV stocks, guarantees a return of 1.4500 and the risk involved in arriving at this return is $4.6 \%$ whereas for the same duration it was observed that market index MP-56 is delivering a return of 0.9211 by taking the risk of $11.80 \%$ while for the same time horizon HV stocks gave a return of -0.099 and the risk involved was $41.1 \%$. The same holds for P-17 and P-20 portfolios of HV stocks, P-37 and P-40 of LV stocks and MP-57 and MP-60 portfolios of market respectively, where it is witnessed that P17 of $\mathrm{HV}$ stocks is giving a return of 2.3600 while during the same phase P-37 of LV stocks was showing a return of 2.325 and MP-57 was delivering a negative return of -0.2975 . However, the risk involved in achieving these returns is projected to be at $8.71 \%$ in the case of LV stocks, $54.35 \%$ for HV stocks and $35.73 \%$ in case of the market respectively. On evaluating the difference in risks incurred and returns earned, it is evident that LV stocks are yielding outstretched returns at moderately lower risk as compared to HV stocks and market indices. Similar opinion is endorsed on analyzing P-20 of HV stocks which is rendering a return of 1.8269 by encountering a risk of $204 \%$, while for the same phase market index (MP-60) is setting a return of 1.475 by attracting a beta of $20.93 \%$, while LV stocks is manifesting a return of 2.065 at a nominal risk rate of $6.36 \%$. The comparison of returns also reflects the same idea that half-yearly LV portfolios have consistently outperformed HV half yearly portfolios when considering the investment to be made with a broader time horizon. It is to be noted that Portfolio's $\mathrm{P}-1$ to $\mathrm{P}-20$ represent High volatility portfolios while $\mathrm{P}-21$ to $\mathrm{P}-40$ represent Low volatility portfolios and MP - 1 to MP - 20 portfolios represent Market values. Likewise, HV and LV represent High Volatility and Low Volatility stocks respectively. 


\begin{tabular}{|c|c|c|c|}
\hline \multicolumn{5}{|c|}{ Sharpe Ratio } \\
\hline Year & HV & LV & Market \\
\hline 2005 -S1 & 0.8573 & 1.1760 & 0.9634 \\
\hline 2006 -S2 & 0.0391 & -0.5995 & 0.1042 \\
\hline 2007 -S3 & -0.1960 & -0.3705 & 0.2292 \\
\hline 2008 -S4 & -0.2610 & -0.1348 & -0.4907 \\
\hline 2009 -S5 & 0.7715 & 1.2265 & 0.7277 \\
\hline 2010 -S6 & -0.2004 & -0.0509 & 0.0591 \\
\hline 2011 -S7 & 0.3405 & 0.2552 & -0.0893 \\
\hline 2012 -S8 & 0.1927 & 0.3925 & 0.1784 \\
\hline 2013 -S9 & 0.5815 & 0.4426 & 0.1816 \\
\hline 2014 -S10 & 0.5623 & 0.7961 & 0.9304 \\
\hline
\end{tabular}

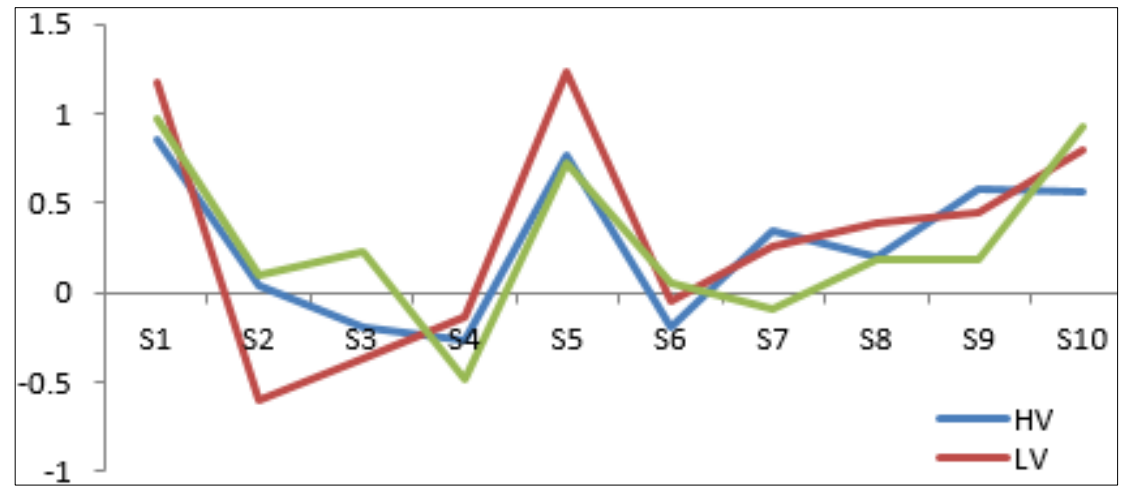

Table 3

RISK/RETURN TRADE-OFF USING SHARPE RATIO

Fig. 3. Sharpe Ratio

Sharpe ratio was developed to compute and characterize risk-return trade-off. It is an essential measure used to evaluate the portfolio performances to understand the risk-adjusted returns. The higher a fund's Sharpe ratio, the better, as it projects higher returns per unit of risk. For the present study, the Sharpe ratio is used to determine portfolios which deliver the highest returns while considering risk. The Sharpe ratio for the present study is computed every year starting from 2005 to 2014. Here S1, S2, and S3....S10 represent the yearly Sharpe values from 2005 to 2014 for ease of analysis. On assessing the Sharpe values of HV, LV monthly portfolios it can be observed that for S1 Sharpe ratio of LV portfolio outperformed $\mathrm{HV}$ and market portfolios as LV portfolios offered a risk-adjusted return of 1.1760 while $\mathrm{HV}$ and market delivered a return of 0.8573 and 0.9634 . Likewise, for S4 all HV, market and LV Sharpe ratios recorded a negative riskadjusted return of $-0.2610,-0.4907$ and -0.1348 respectively; however, the performance of LV portfolios delivered better returns over their HV and market counterparts for S4. Related observations of the shape ratios during S5 reveals that HV and market are offering a risk/return tradeoff of 0.7715 and 0.7277 , LV portfolios delivered a Sharpe return of 1.2265 which outmatched the returns offered by both HV and market. It is notable that the performance of LV portfolios for the year S6 and S10 surpassed their HV counterpart. Similarly, S8 also marked the outperformance of LV portfolios over HV and market, with LV portfolios offering a risk-adjusted return of 0.3925 outperforming HV and market which offered 0.1927 and 0.1784 respectively. On evaluating the Sharpe ratios of LV, HV and Market portfolios, we observe that LV portfolios have offered higher risk-adjusted returns for the period under study, as compared to HV and Market portfolios.

\section{Conclusions}

Prospective investors with broad time horizon are suggested to invest in stocks of GlaxoSmithKline Pharmaceuticals Limited, Britannia Industries Limited, GlaxoSmithKline Consumer Healthcare Limited, Infosys Limited, Dr Reddy's Laboratories Limited and Gillette India Limited. These stocks have registered superior absolute returns as well as riskadjusted returns consistently over other stocks, thus promising to be a prudent choice for risk-averse investors with a broad investment horizon. The present study confirms that portfolio consisting of low volatility stocks portfolio consistently outperforms the market as well as high volatility stocks portfolio, i.e., stocks with low historical volatility exhibit superior risk-adjusted returns and higher absolute returns over high volatility stocks and market index when invested over a long period, thus marking the presence of low-risk anomaly. Risk anomaly facilitates outperformance of low volatility stocks not only on a risk-adjusted basis but also on an absolute basis during the period of our study. The existence of low-risk anomaly has made the investors take due diligence before investing in high volatility stocks. This approach of low volatility investment is a better strategy principally when the market is not exhibiting any specific trends, 
furthermore when the market, in general, is highly volatile. The study implies that over a long duration low-risk anomaly offers an opportunity to earn superior returns at much lower risk over to market-weighted benchmark portfolio, thus proving inefficiency in the Indian equity market and reaffirming the existence of risk anomaly as inferred from various other empirical studies.

\section{References}

1.ANG, A. Asset Management. A Systematic Approach to Factor Investing, Oxford University Press, 2014.

2.BAKER, B., BRADLEY, B., TALIAFERRO, R. The Low-Risk Anomaly- A Decomposition into Micro and Macro Effects. Financial Analysts Journal, 2013; 70, 43-58.

3.SUDARVEL, D. R. Indian Stock Market Anomalies: A Literature Review, International Journal of Advance Research in Computer Science and Management Studies, 2015; 3(2): 173-8.

4.WADHWA, V. G. Low Volatility Anomaly in India- An Empirical Analysis. International Journal of Commerce, Business and Management, International Journal of Commerce, Business and Management, 2014; 3(1): 100-4.

5.*** Ministry of Commerce and Industry, Government of India, India Brand Equity Foundation, Available online at https://www. ibef.org/ industry/pharmaceutical-india.aspx.

$\overline{\text { Manuscript received: } 4.06 .2019}$ 